\title{
Process simulations for 3D turning using uniform and variable microgeometry PCBN tools
}

\author{
Y. Karpat \\ Department of Industrial Engineering, \\ Bilkent University, \\ Ankara 06800, Turkey \\ E-mail: ykarpat@bilkent.edu.tr
}

\section{T. Özel*}

Department of Industrial and Systems Engineering,

Rutgers University,

Piscataway, NJ 08854, USA

E-mail: ozel@rci.rutgers.edu

${ }^{*}$ Corresponding author

\begin{abstract}
In this paper, uniform and variable edge microgeometry design inserts are utilised and tested for 3D turning process. In 3D tool engagement with workpiece, thickness of the chip varies from a maximum equal to the feed rate (at primary cutting edge) to a minimum on the tool's corner radius (at trailing cutting edge). The ideal tool edge preparation should posses a variable configuration which has larger edge radius at the primary cutting edge than at the trailing cutting edge. Here the key parameter is the ratio of uncut chip thickness to edge radius. If a proper ratio is chosen for given cutting conditions, a variable cutting edge along the corner radius can be designed or 'engineered'. In this study, Finite Element Modelling (FEM)-based 3D process simulations are utilised to predict forces and temperatures on various uniform and variable edge microgeometry tools. Predicted forces are compared with experiments. The temperature distributions on the tool demonstrate the advantages of variable edge microgeometry design.
\end{abstract}

Keywords: variable microedge geometry tool design; 3D turning; Finite Element Modelling; FEM.

Reference to this paper should be made as follows: Karpat, Y. and Özel, T. (2008) 'Process simulations for 3D turning using uniform and variable microgeometry PCBN tools', Int. J. Machining and Machinability of Materials, Vol. 3, No. 3, pp.250-262.

Biographical notes: Y. Karpat received a $\mathrm{PhD}$ in Industrial and Systems Engineering from Rutgers University, USA in 2007. Currently, he is an Assistant Professor of Industrial Engineering at Bilkent University, Turkey. His research interest includes analytical and computational modelling of machining processes, optimisation of manufacturing processes using evolutionary algorithms, computational intelligence in multicriteria decision making. He has published over 10 refereed papers.

T. Özel received a $\mathrm{PhD}$ in Mechanical Engineering from The Ohio State University, USA in 1998. He is an Assistant Professor of Industrial and Systems Engineering at Rutgers University. His research interest includes 
modelling of machining processes, automation and process control, optimisation of processes and systems, and micro/nanomanufacturing. He has over 10 years of experience in manufacturing research. He has been a Reviewer, Organiser, Guest Editor and Editorial Board Member for several journals and conferences. He has published over 50 refereed papers.

\section{Introduction}

Metal cutting operations still represent the largest class of manufacturing operations where turning is the most commonly employed material removal process. In advanced turning operations such as hard turning, PCBN cutting tools with edge preparation (honed, chamfered or waterfall edges) preferred to protect the cutting edge from chipping. Edge preparation should be carefully selected for a given application because it affects the surface properties of the workpiece in terms of surface integrity.

In recent years, 3D Finite Element Analysis (FEA) has become available to calculate and simulate the process variables such as forces, temperature and stress distributions, etc. during machining. There are numerous studies on FEA of orthogonal machining, which provides information about plane strain/plain stress analysis for the mechanics of cutting, yet the studies on Finite Element Modelling (FEM) of 3D machining is limited. 3D FEA-based process models is needed to study practical machining operations. Ceretti et al. (2000) developed a 3D FEA model for turning to predict forces, temperature and stress distributions for the machining of aluminium alloys and low-carbon steels under orthogonal and oblique cutting configurations. Guo and Dornfeld (1998) presented a 3D FEA model to simulate burr formation when drilling stainless steel. They emphasised the importance of proper definition of work material properties and friction conditions. Guo and Liu (2002) proposed a 3D FEA model for hard turning of AISI 52100 steel using PCBN tools. Their model was used to predict the temperature distribution over the cutting edge, the residual stress distribution on the machined surface and forces. They stressed that there is a need for a method which yields rake face friction factor or coefficient of friction values. In a recent study, Liu and Shih (2006) compared the predictions of a 3D FEA model with experimental measurements for turning of titanium. They also investigated the effects of edge preparations on process variables and observed that increasing cutting speed raises tool temperature, decreases cutting forces; increasing edge radius, decreases tool temperatures and increases cutting forces. In their simulations they were also able to demonstrate serrated chip formation in the machining of titanium. Recently, the authors have studied effects of uniform chamfered and honed edge microgeometry in 3D turning using 3D FEA (Karpat and Özel, 2007). In that study, they also explored the influence of work material models and friction factor on predicted process variables such as forces and temperatures.

\subsection{Mechanics of $3 D$ turning}

A general schematic of 3D turning is shown in Figure 1, where the cutting process is defined by the cutting speed $(V)$, feed rate $(f)$ and depth of cut $(d)$. The resulting forces, namely tangential force $\left(F_{z}\right)$, radial force $\left(F_{x}\right)$ and feed or axial force $\left(F_{y}\right)$ with their directions are also shown in Figure 1. For turning of alloy steels, typically low depth of 
cut and feed rates are used. The detailed interaction of the cutting tool and workpiece is explained in Figure 2. It can be seen that chip load is a function of depth of cut, feed rate and tool corner radius. In this figure, it is important to observe that the thickness of the chip, which is shown as the hatched area, varies along tool corner radius.

Figure 1 A schematic of 3D turning

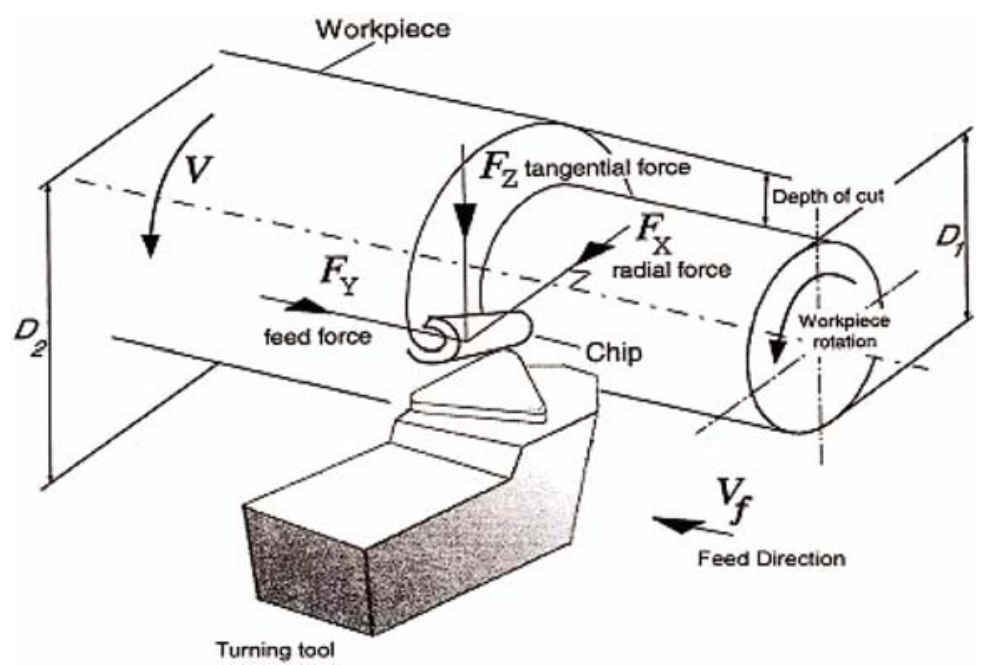

Source: Altintas (2000).

Figure 2 Chip load in typical turning operation with a corner radius tool
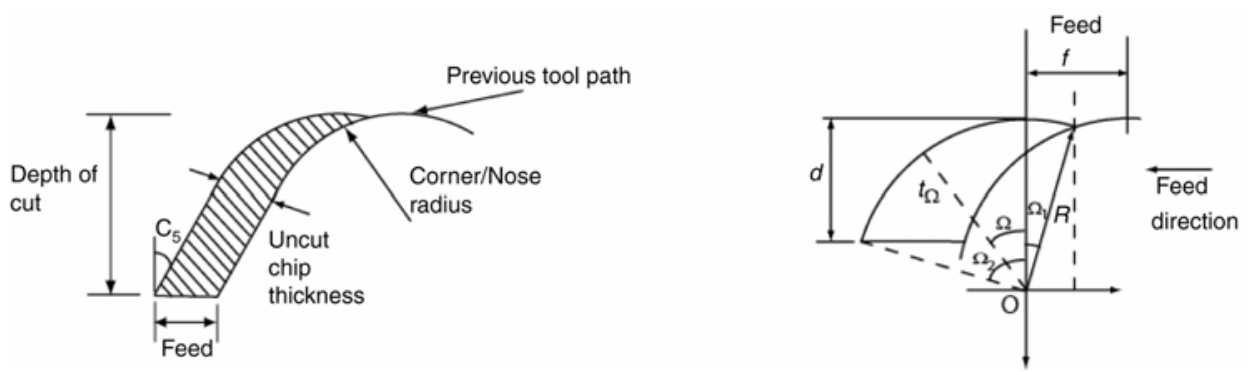

Assuming rake and inclination angles introduced by the tool holder are zero, maximum uncut chip thickness and the variation of chip thickness along the chip can be calculated as follows:

$$
\begin{aligned}
& \Omega_{1}=-\sin ^{-1}\left(\frac{f}{2 R}\right) \\
& \Omega_{2}=\cos ^{-1}\left(\frac{R-d}{R}\right) \\
& t_{\Omega}=R+f \sin \Omega-\sqrt{R^{2}-f^{2} \cos ^{2} \Omega} \quad \text { when } \quad \Omega \leq \tan ^{-1}\left(\frac{R \sin \Omega_{2}-f}{R-d}\right) \\
& t_{\Omega}=R-\frac{R-d}{\cos \Omega} \quad \text { when } \quad \Omega>\tan ^{-1}\left(\frac{R \sin \Omega_{2}-f}{R-d}\right)
\end{aligned}
$$


Figure 3 shows the chip thickness with respect to sweep angle $\Omega$ for a given cutting condition.

Figure 3 Variation of uncut chip thickness (see online version for colours)
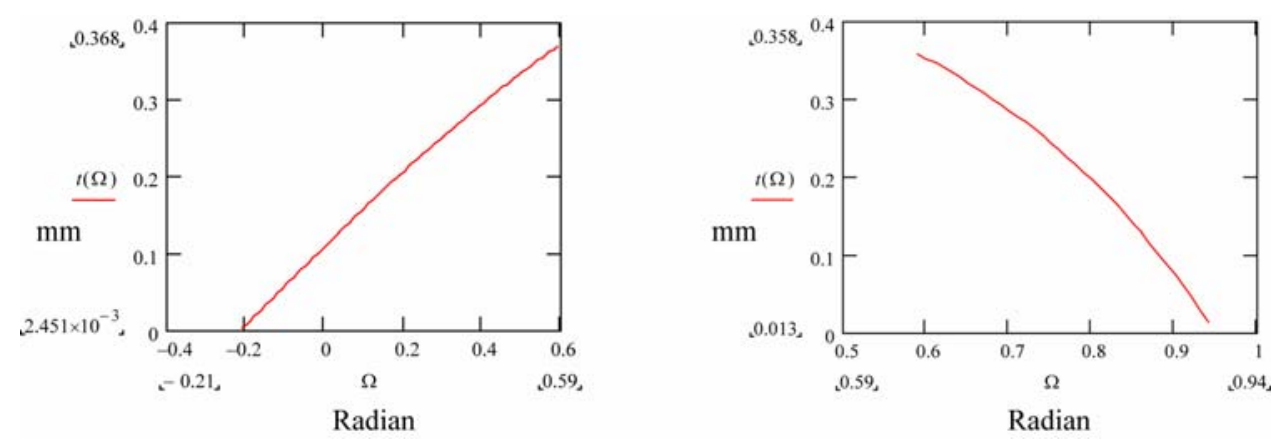

The distribution of chip loads on the insert can be determined as a function of angle $\Omega$ along corner radius of the tool. As shown in Figure 3, the chip thickness becomes very small for a considerable range of angle $\Omega$ along corner radius.

It was shown that a ratio of uncut chip thickness to edge radius around 3 is suitable for machining AISI 4340 steel with curvilinear edge CBN cutting tools (Karpat and Özel, 2006). In a similar study, this ratio is found to be around 2 by Endres and Koutanya (2002) after tool wear tests for a different workpiece-tool material. However, it is clear from Figure 3 that the ratio does not stay constant along the tool corner radius and decreases continuously towards the end of contact point if uniform edge design cutting tools are employed. It is believed that if a proper ratio of edge preparation to uncut chip thickness can be maintained along tool corner radius, significant advantages such as prolonged tool life and superior surface finish can be obtained. This is explained in the following section.

\subsection{Advanced cutting tool microgeometry design}

Edge preparation enhances tool life but at the same time makes cutting less efficient especially when the ratio of uncut chip thickness to tool edge radius decreases. Karpat and Özel (2006) have shown that friction factor increases with decreasing uncut chip thickness to edge radius ratio. Due to trapped work material at the trailing edge of the cutting tool, cutting cannot be performed efficiently which results in increased strains at that region and high temperatures. In order to explain this in detail, let us reconsider Figure 2 which demonstrates the chip load during 3D machining.

As explained before, the thickness of the chip varies from a maximum equal to the feed rate to a minimum on the tool's corner radius. If a uniform edge radius applied along the corner radius of the cutting tool, cutting efficiency will be low due to small ratio of uncut chip thickness to tool edge radius around the trailing edge. Large edge radius will not be able to machine that area but rub (burnish) it against the workpiece. Three critical sections $A-A, B-B$ and $C-C$ are demonstrated in Figure 4.

In Section $A-A$, which is leading cutting edge, uncut chip thickness is greater than the edge radius which indicates regular cutting. In Section $B-B$, at the end of the leading 
edge, the uncut chip thickness is equal to the edge radius, where the rubbing (burnishing) action becomes more dominant than shearing. In Section $C$ - $C$, at the trailing edge, the edge radius is larger than the thickness of the uncut chip and work material is rubbed against the workpiece. This rubbing action (burnishing), which results in increased temperatures on the tool and workpiece surfaces is believed to hinder the performance of the tool.

Figure 4 (a) Uniform versus variable edge design on a tool insert and (b) CAD model of the variable hone edge design (see online version for colours)
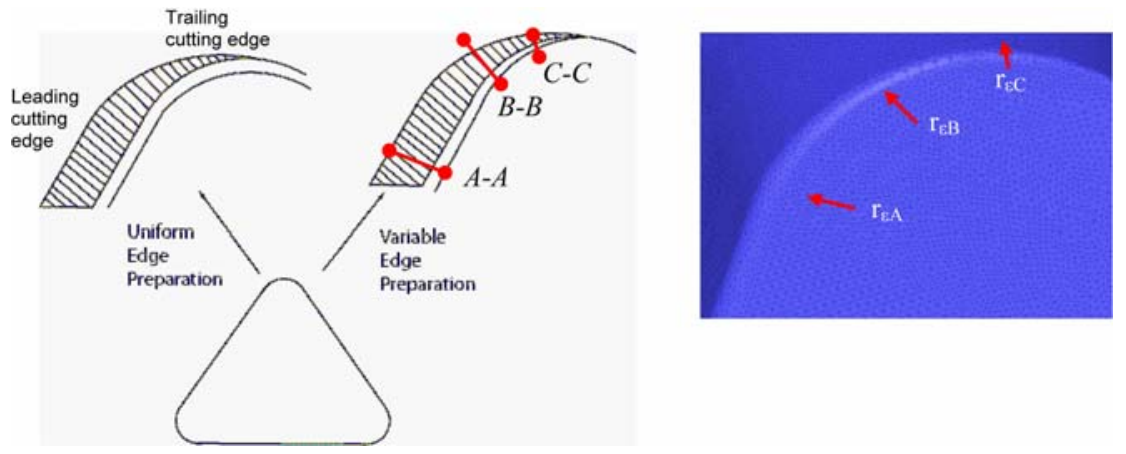

Computer controlled honing devices enable the production of cutting tools with 'engineered' microgeometry or cutting tools with variable edge preparation, where the edge radius along the corner radius of the cutting tool changes as a function of the thickness of the chip (Conicity Technologies, 2006). A CAD model of a variable edge design tool insert along with a finite element mesh (min. element size $<10 \mu \mathrm{m}$ ) is shown in Figure 4(b). This figure shows the tip of a cutting tool with variable edge preparation, $r_{\varepsilon}(\Omega)$. The edge radii at point $A$ and $C$ are $0.05 \mathrm{~mm}$ and $0.01 \mathrm{~mm}$, respectively where $r_{\varepsilon_{A}}>r_{\varepsilon_{B}}>r_{\varepsilon_{C}}$.

The purpose of this design is to eliminate the rubbing (burnishing) action at trailing edge of the tool by decreasing the edge radius towards the tip of the tool. This will reduce the unwanted excessive heat generation at the trailing zone and increase the performance of the tool. Proper tool edge design for the process in hand can be made only when tool-chip friction and heat generation mechanisms at the tool-chip and tool-workpiece interfaces are understood. In variable edge design, the key parameter is the ratio of uncut chip thickness to edge radius, $\lambda=t(\Omega) / r_{\varepsilon}(\Omega)$. If this ratio is known, for a particular cutting condition a variable cutting edge can be designed. Variable edge preparation is not limited to honed microgeometry inserts. Chamfered and waterfall type microgeometry inserts can also have variable edge preparation. As for variable chamfered edge design, the goal will be to calculate optimum chamfer angle and chamfer height for given uncut chip thickness along the cutting edge as detailed in Klocke and Kratz (2005). The purpose of continuously changing the chamfer angle along the corner radius is to alter the locations of high temperature zones and reduce the possibility of a crater wear formation.

A methodology is proposed for advanced cutting tool microgeometry design as shown in the flowchart in Figure 5. For a given cutting condition values of suggested tool nose/corner radius $(R)$ can be obtained from tool manufacturers. Tool edge radius $\left(r_{\varepsilon}\right)$ must be selected in accordance with tool corner radius. It should be noted that the friction 
identification method for microgeometry tools proposed in Karpat and Özel (2006) is at the core of this design methodology. Cutting conditions and workpiece material affect the friction conditions and this information is built into 3D finite element model. The field variables obtained from 3D process simulations such as temperature and stress distributions, tool wear, cutting forces etc. are utilised in assessing the performance of cutting tools or selecting cutting conditions for a given edge preparation.

In order to investigate the performance of cutting tools with various edge preparations, tools with uniform and variable edge preparations provided by Conicity Technologies have been used in machining tests. The experimental procedure is explained in the following section.

Figure 5 Flowchart of advanced cutting tool microgeometry design

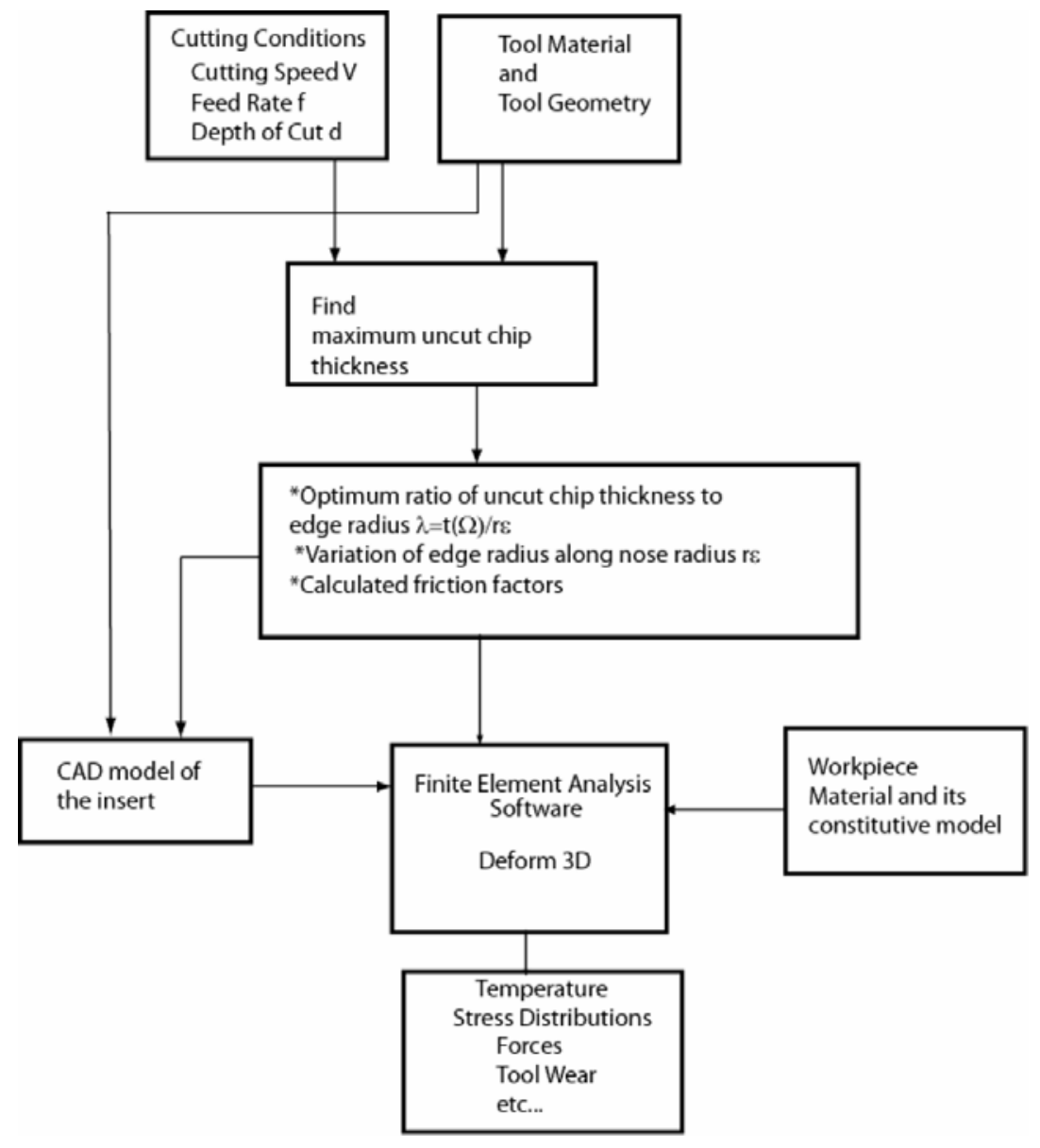

\section{Experimental procedure}

In this study, turning of AISI 4340 steel (hardness of 20 HRC) using PCBN inserts with nine different microgeometries (uniform chamfer with $0.1 \mathrm{~mm}$ chamfer height and $20^{\circ}$ angle, uniform hone with $50 \mu \mathrm{m}$ edge radius, uniform hone with $40 \mu \mathrm{m}$ edge radius, 
uniform waterfall hone with $20-40 \mu \mathrm{m}$ edge dimensions, uniform waterfall hone with 25-50 $\mu \mathrm{m}$ edge dimensions, uniform waterfall hone with 30-60 $\mu \mathrm{m}$ edge dimensions, variable hone with $r_{\varepsilon_{A}}=50 \mu \mathrm{m}, r_{\varepsilon_{B}}=10 \mu \mathrm{m}$ edge radii, variable waterfall hone with $r_{\varepsilon_{A}}=25-50 \mu \mathrm{m}, \mathrm{r}_{\varepsilon_{B}}=10 \mu \mathrm{m}$ edge radii and variable hone with $r_{\varepsilon_{A}}=30-60 \mu \mathrm{m}$ $r_{\varepsilon_{B}}=10 \mu \mathrm{m}$ edge radii was considered. Field Emission Scanning Electron Microscopy (FESEM) images of edge preparations are shown in Figure 6.

Figure 6 Images of PCBN inserts at 50 times magnification obtained with scanning electron microscopy: (a) chamfered, (b) uniform honed with $50 \mu \mathrm{m}$ radius, (c) variable hone with 10 to $50 \mu \mathrm{m}$ radius and (d) uniform waterfall hone $60-30 \mu \mathrm{m}$

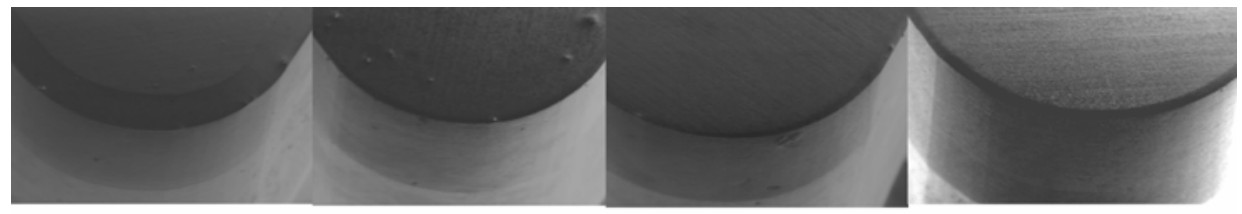

(a)

(b)

(c)

(d)

Bar turning experiments were conducted using a cylindrical bar specimen with a diameter of 2.8 inches $(71 \mathrm{~mm})$ and length of 12 inches $(305 \mathrm{~mm})$. Solid top PCBN inserts (TNG-423) were used with a Kennametal MTGNR-123B right hand tool holder that provided $0^{\circ}$ lead, $-5^{\circ}$ side rake, and $-5^{\circ}$ back rake angles. The forces were measured with a three-component force dynamometer (Kistler Type 9121) mounted on the turret disk of the CNC lathe. The charge signal generated at the dynamometer was amplified using charge amplifiers (Kistler Type 5814B1), acquired and sampled by using data acquisition PCMCIA card and Kistler DynoWare software on a laptop computer. Table 1 summarises the experimental cutting conditions.

Table 1 Cutting conditions used in experiments (marked by $\square$ ) and simulations (marked by $\boldsymbol{~}$ )

\begin{tabular}{lcccc}
\hline Cutting conditions & \multicolumn{4}{c}{ Tool type } \\
\cline { 2 - 5 } & Hone 50 & WF 30-60 & Var hone 50 & Chamfered \\
\hline$V=125 \mathrm{~m} / \mathrm{min}, f=0.15 \mathrm{~mm}, d=1 \mathrm{~mm}$ & $\square$ & $\square$ & $\square$ & $\square$ \\
$V=125 \mathrm{~m} / \mathrm{min}, f=0.1 \mathrm{~mm}, d=1 \mathrm{~mm}$ & $\square$ & $\square$ & $\square$ & $\square$ \\
$V=175 \mathrm{~m} / \mathrm{min}, f=0.15 \mathrm{~mm}, d=0.5 \mathrm{~mm}$ & $\square$ & $\square$ & $\square$ & $\square$ \\
$V=175 \mathrm{~m} / \mathrm{min}, f=0.1 \mathrm{~mm}, d=0.5 \mathrm{~mm}$ & $\square$ & $\square$ & $\square$ & $\square$ \\
\hline
\end{tabular}

The force measurements were replicated three times. The averages of the measured forces are shown in Figures 7 and 8. Similar to the results of orthogonal cutting, the effect of edge preparation became apparent on radial force $\left(F_{x}\right)$ measurements.

The force measurements obtained from various edge preparation tools are again found to be similar. For the cutting condition of $V=125 \mathrm{~m} / \mathrm{min}, f=0.15 \mathrm{~mm} / \mathrm{rev}$, $d=1 \mathrm{~mm}$, variable waterfall hone edge with 30-60 $\mu \mathrm{m}$ edge dimension yielded the lowest radial forces followed by variable hone $50 \mu \mathrm{m}$ edge radius as shown in Figure 7(a). These two variable edge preparations produced higher tangential forces $\left(F_{y}\right)$ than other edge preparations. This result may imply that more efficient cutting due to 
variable edge preparation results in lower radial forces but slightly higher tangential forces. It must be noted that the ratio of feed to tool edge radius was three in that cutting condition.

Figure 7(b) shows the force measurements for the cutting condition of $V=125 \mathrm{~m} / \mathrm{min}, f=0.1 \mathrm{~mm} / \mathrm{rev}, d=1 \mathrm{~mm}$, where the feed rate is decreased compared to previous cutting condition. Decreasing feed rate resulted in lower tangential forces. In this cutting condition, variable honed tool with $50 \mu \mathrm{m}$ edge radius yielded the lowest radial force. Variable edge designs again performed well under this cutting condition.

Figure 7 Measured forces (a) $V=125 \mathrm{~m} / \mathrm{min}, f=0.15 \mathrm{~mm} / \mathrm{rev}, d=1 \mathrm{~mm}$ and (b) $V=125 \mathrm{~m} / \mathrm{min}$, $f=0.1 \mathrm{~mm} / \mathrm{rev}, d=1 \mathrm{~mm}$ (see online version for colours)

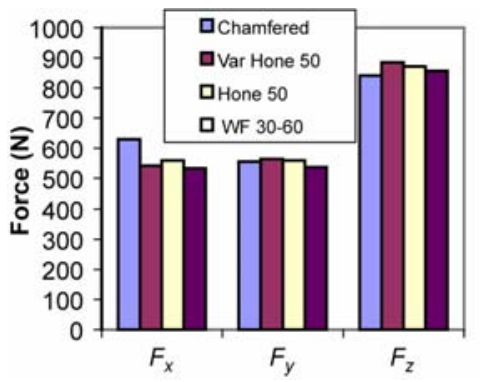

(a)

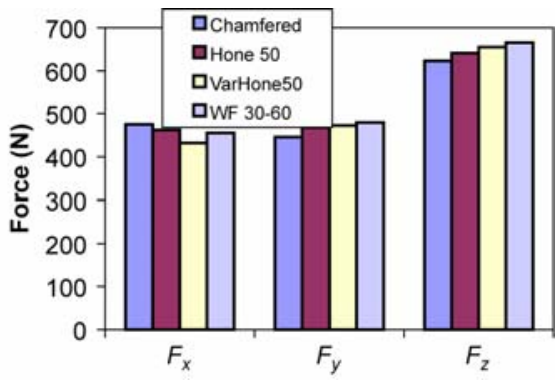

(b)

Figure 8 demonstrates the force measurements when depth of cut is decreased to $0.5 \mathrm{~mm}$. It must be noted that the corner radius of the cutting tools used in our experiments are $R=1.2 \mathrm{~mm}$, which means that the cutting will be performed by the tip of the tool $(d<R)$. As expected, the rubbing effects are expected to be dominant in this cutting condition case, which is evident from radial forces nearly equal to tangential forces. Variable edge preparation yielded the lowest radial force.

It must be noted that, in this study, no attempts were made to validate edge preparation dimensions. It is known that the dimensions may vary from tool to tool due to inaccuracies during edge preparation process. As an example, variable waterfall hone with 30-60 $\mu \mathrm{m}$ edge dimension yielded unexpectedly high force measurements in Figure 8 might be due to above mentioned reasons.

Figure 8 Measured forces at the cutting condition of $V=175 \mathrm{~m} / \mathrm{min}, f=0.15 \mathrm{~mm} / \mathrm{rev}$, $d=0.5 \mathrm{~mm}$ (see online version for colours)

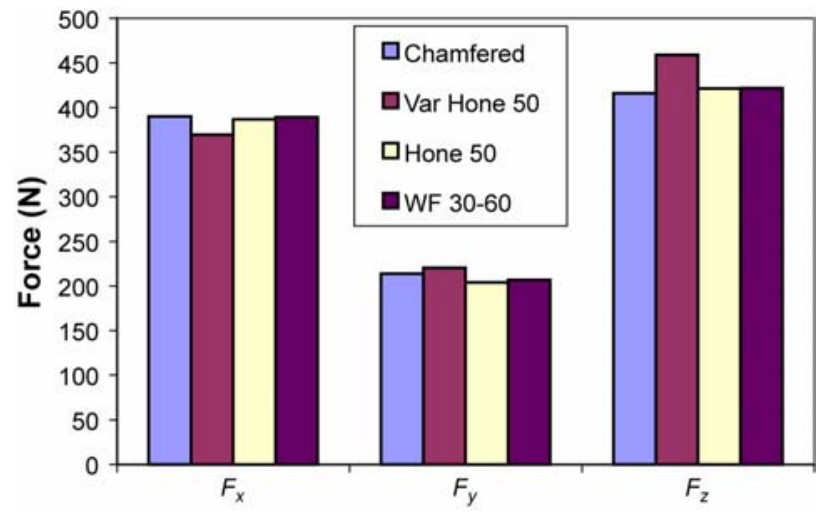




\section{Finite element modelling of 3D hard turning}

Accurate and reliable flow stress models are considered highly necessary to represent work material constitutive behaviour under high-speed cutting conditions especially for a new material. A number of empirical and semiempirical constitutive models have been developed to model flow stress with certain accuracy in high-speed cutting. Among many other material constitutive models, Johnson-Cook model (1983) is widely used for high-strain rate applications. This constitutive model describes the flow stress of a material with the product of strain, strain rate and temperature effects that are individually determined as given in Equation (2). In the Johnson-Cook (J-C) model, the constant $A$ is in fact the initial yield strength of the material at room temperature and a strain rate of $1 / \mathrm{s}$ and $\bar{\varepsilon}$ represents the plastic equivalent strain. The strain rate $\dot{\bar{\varepsilon}}$ is normalised with a reference strain rate $\dot{\bar{\varepsilon}}_{0}$. Temperature term in the $\mathrm{J}$-C model reduces the flow stress to zero at the melting temperature of the work material, leaving the constitutive model with no temperature effect.

$$
\bar{\sigma}=\left[A+B(\bar{\varepsilon})^{n}\right]\left[1+C \ln \left(\frac{\dot{\bar{\varepsilon}}}{\dot{\overline{\varepsilon_{0}}}}\right)\right]\left[1-\left(\frac{T-T_{\text {room }}}{T_{\text {melt }}-T_{\text {room }}}\right)^{m}\right]
$$

In this study, a FEA software (Deform 3D) is used to study the effects of uniform chamfered, uniform honed and variable honed edge preparations. The workpiece is modelled as rigid-perfectly plastic material where the material constitutive model of this deformable body is represented with Johnson-Cook (1983) material model where $A=1504 \mathrm{MPa}, B=569 \mathrm{MPa}, n=0.22, C=0.003, m=0.9$ are the parameters for AISI 4340 steel as given by Gray et al. (1994). Workpiece is represented by a curved model with $70 \mathrm{~mm}$ diameter which is consistent with the experimental conditions. Only a segment $\left(15^{\circ}\right)$ of the workpiece was modelled in order to keep the size of mesh elements small. Workpiece model includes 140,000 elements. The bottom surface of the workpiece is fixed in all directions. The cutting tool is modelled as a rigid body, which moves at the specified cutting speed by using 100,000 elements. Thermal boundary conditions are defined accordingly in order to allow heat transfer from workpiece to cutting tool. The FEM software DEFORM 3D is based on an implicit Lagrangian computational routine with continuous adaptive remeshing. A very fine mesh density is defined at the tip of the tool and at the cutting zone to obtain fine process output distributions. The minimum element size for the workpiece mesh was set to $0.015 \mathrm{~mm}$. All simulations were run at the same cutting condition (cutting speed of $V=125 \mathrm{~m} / \mathrm{min}$, feed rate of $f=0.15 \mathrm{~mm} / \mathrm{rev}$ and depth of cut of $d=1 \mathrm{~mm}$ ). A workpiece material damage model proposed by Cockcroft and Latham (1966) was also used in simulations.

Process simulations are very sensitive to friction model used at the tool/chip-workpiece interface. Usually a constant friction factor or coefficient of friction is used to define friction model. It is well known that friction modelling is more complex than that and requires the information of sticking and sliding regions. However, definition of these regions in $3 \mathrm{D}$ cutting is not as straightforward as orthogonal 2D cutting since chip load varies on the rake face of the tool. In order to investigate the effect of friction factor on finite element simulation outputs, a sensitivity analysis is performed. The effect of three different friction factors on the process outputs such as predicted forces and maximum tool temperatures are shown for honed and variable hone cutting tools in Table 2. 
Table 2 The effect of friction factor on process outputs

\begin{tabular}{|c|c|c|c|c|c|c|c|c|}
\hline \multirow{2}{*}{$\begin{array}{l}\text { Friction } \\
\text { Factor }\end{array}$} & \multicolumn{4}{|c|}{ Variable hone 50} & \multicolumn{4}{|c|}{ Uniform hone 50} \\
\hline & $F_{x}(N)$ & $F_{z}(N)$ & $F_{y}(N)$ & $\begin{array}{c}\text { Tool } \\
\text { temp. }{ }^{\circ} \mathrm{C}\end{array}$ & $F_{x}(N)$ & $F_{z}(N)$ & $F_{y}(N)$ & $\begin{array}{c}\text { Tool. } \\
\text { temp. }{ }^{\circ} \mathrm{C}\end{array}$ \\
\hline 0.4 & 220 & 635 & 220 & 545 & 278 & 820 & 390 & 630 \\
\hline 0.7 & 260 & 785 & 270 & 656 & 362 & 900 & 500 & 760 \\
\hline 0.85 & 380 & 820 & 390 & 690 & 440 & 939 & 515 & 775 \\
\hline
\end{tabular}

According to these results, as friction factor increases, forces and tool temperatures increase as expected. Decreasing friction factor results in thinner and curled chips. Figure 9 shows the simulated and measured forces, it can be seen that finite element simulation tends to under-predict the radial and feed forces while tangential force prediction is in agreement with measured forces. In obtaining the results given in Figure 9 , friction factors of $0.9,0.92,0.85$ and 0.8 are found to be the most suitable for the simulations with uniform chamfered, uniform honed, variable honed and waterfall honed inserts, respectively. The reason honed tools have lower friction factor may be related to its blunter edge compared to variable hone and chamfered tools. The FEM software DEFORM 3D version 5.0 does not allow user to define friction windows, where sliding and sticking regions can be defined. It allows the definition of friction factor as a function of normal pressure, however, this approach also did not improve radial and feed force predictions and yielded similar results to those obtained with constant friction factor definition of interface friction between tool and workpiece. It must be noted that even though a higher friction factor used in simulations, variable hone force predictions are still lower than honed and chamfered tools.

Figure 9 Comparison of measured and simulated forces for various microgeometry inserts (see online version for colours)

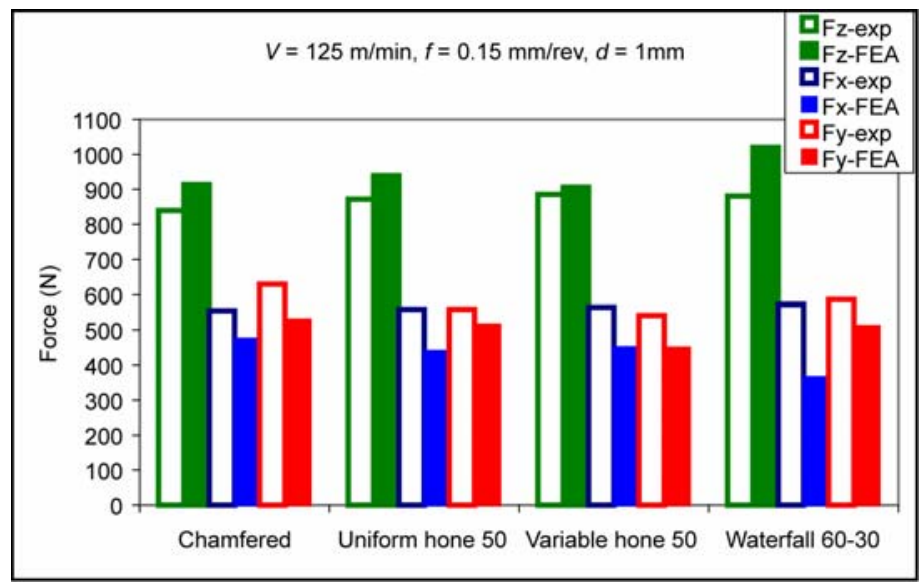

Predicted temperature distributions on the tool are shown in Figure 10 for three different edge preparation inserts. Temperature distributions in Figure 10 depict that smallest hot zone formed on the variable honed tool and maximum temperatures of $710^{\circ} \mathrm{C}, 775^{\circ} \mathrm{C}$, $763^{\circ} \mathrm{C}$ and $801^{\circ} \mathrm{C}$ were predicted for variable honed, uniform honed, uniform chamfered and waterfall honed inserts, respectively. 
Figure 10 Temperature distributions simulated for machining with (a) variable honed $r_{\varepsilon}=10-50 \mu \mathrm{m}$, (b) uniform honed $r_{\varepsilon}=50 \mu \mathrm{m}$, (c) uniform chamfered and

(d) waterfall hone 60-30 $\mu \mathrm{m}$ inserts (see online version for colours)

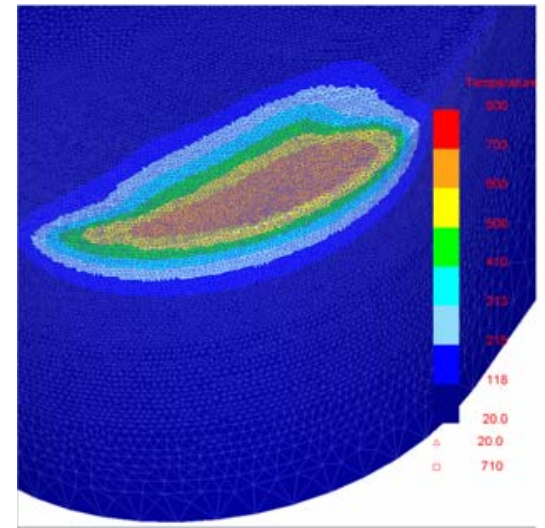

(a)

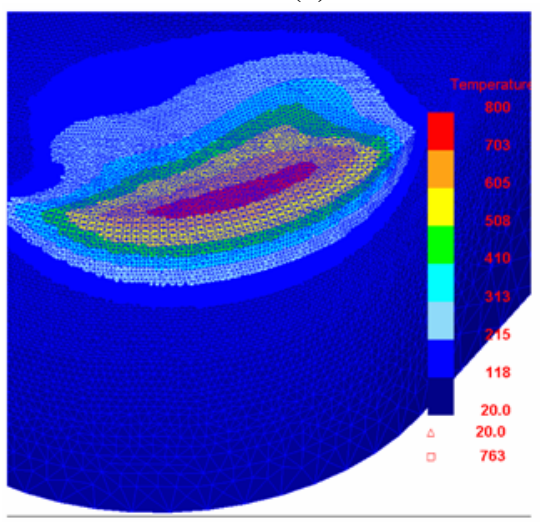

(c)

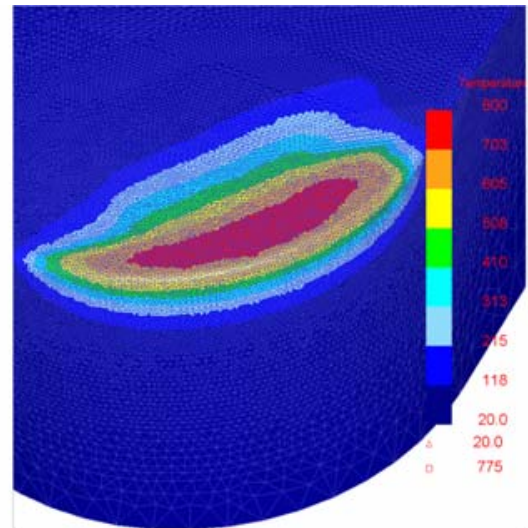

(b)

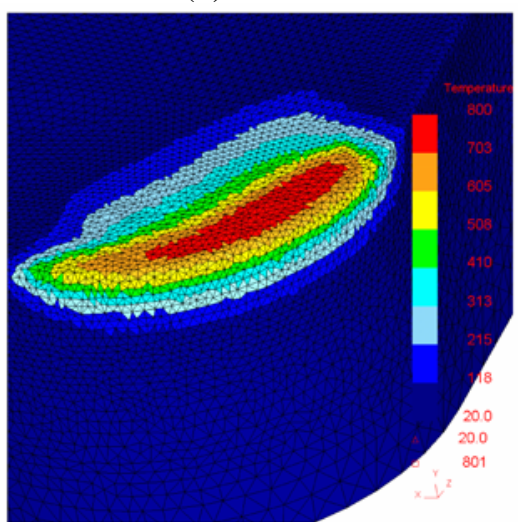

(d)

On the other hand, the friction factor must increase at the trailing edge of the cutting tool. This increase is also believed to affect the chip morphology. In order to investigate the effects of various edge preparations on chip morphology, the photographs of collected chips (cutting speed of $V=125 \mathrm{~m} / \mathrm{min}$, feed rate of $f=0.15 \mathrm{~mm} / \mathrm{rev}$ and depth of cut of $d=1 \mathrm{~mm}$ ) are shown in Figure 11 and measurements of chip curling (diameter and pitch) taken from chips are listed in Table 3.

It is observed that, uniform edge preparations resulted in chips smaller in diameter and pitch than variable edge preparations. The chips produced by uniform hone $50 \mu \mathrm{m}$ and uniform waterfall 30-60 $\mu \mathrm{m}$ are quite similar. Chamfered tool produced long and straight chips which are not desirable in practical cutting conditions since they tend to accumulate around the cutting edge and scratch the surface. Temperature distributions in the chip and workpiece for uniform chamfered, uniform honed and variable hone obtained from finite element simulations are shown in Figure 10. Workpiece temperatures are observed to be higher, when machining with chamfered tools. Figure 11 demonstrates the effectiveness of using variable hone edge preparation. Effective strains at the root of the chip are found to be lower in variable edge design which confirms the 
basic premise of variable edge design. Low strains, which mean less rubbing action, are believed to decrease cutting temperatures at the trailing edge of the cutting tool. SEM images of the chips produced by these edge preparations are shown in Figure 12, where continuous chips were obtained with a little serration.

Figure 11 Effective strain distributions at the cutting zone for (a) uniform honed $r_{\varepsilon}=50 \mu \mathrm{m}$,

(b) variable honed $r_{\varepsilon}=10-50 \mu \mathrm{m}$ and (c) waterfall hone $60-30 \mu \mathrm{m}$ inserts (see online version for colours)

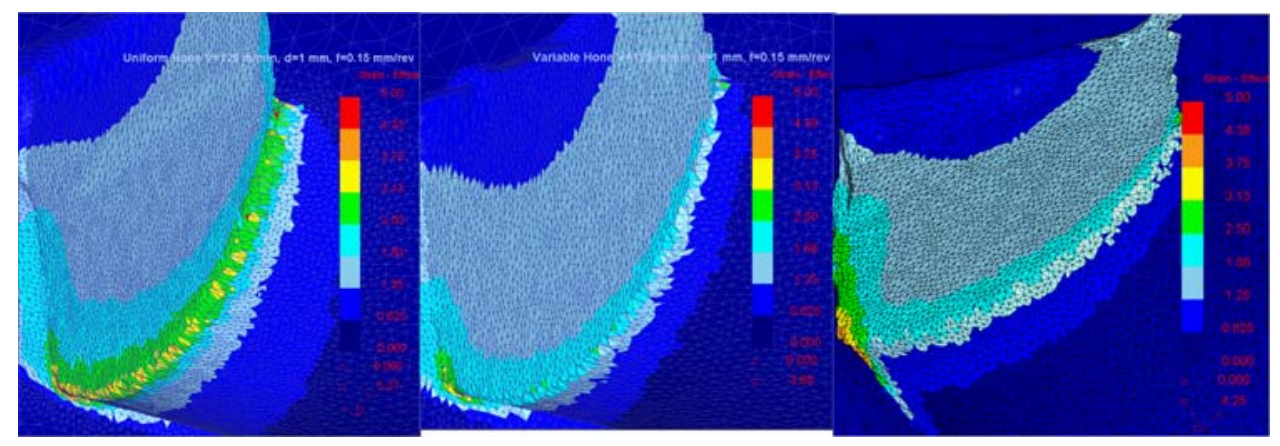

(a)

(b)

(c)

Figure 12 SEM images of chip shapes produced by (a) uniform chamfered, (b) uniform honed and (c) variable hone inserts

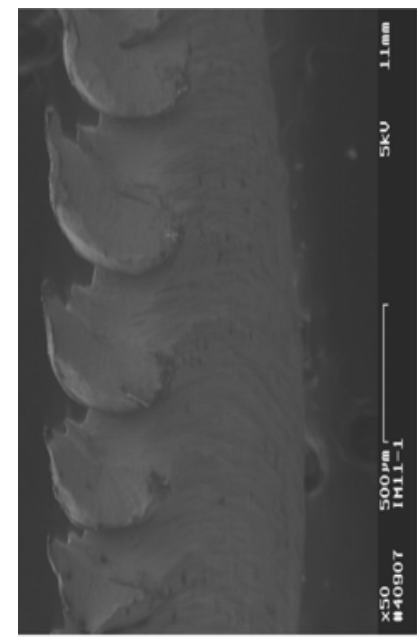

(a)

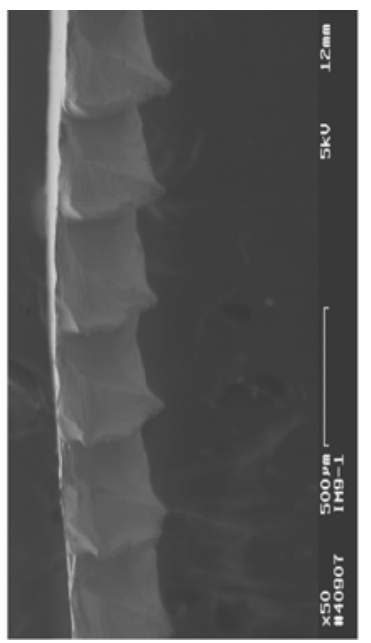

(b)

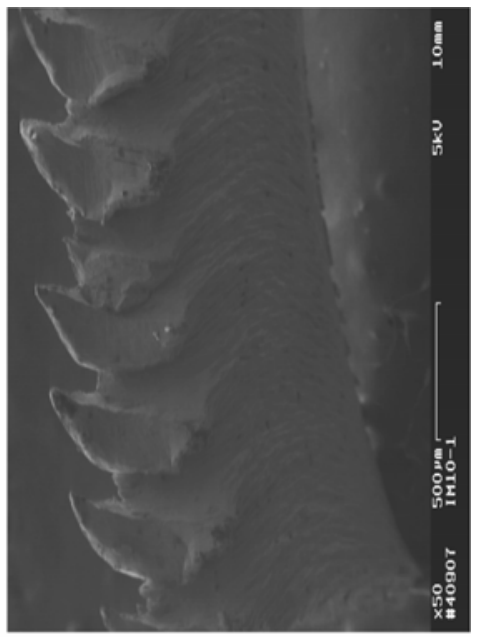

(c)

\section{Conclusions}

In this study, a methodology is proposed for variable cutting tool microgeometry design. Bar turning experiments and 3D FEA are performed to compare uniform and variable edge preparations. These results revealed that the variable edge preparation inserts perform better than uniform edge preparation counterparts if the variable edge is properly designed for the given cutting conditions. 3D FEA based process simulations are utilised 
for predicting forces, stresses and tool wear. Tool wear simulations are considered to represent combined effect of normal stress and temperatures which clearly demonstrated the effectiveness of variable edge preparations. The effect of edge preparation on chip formation is investigated. Preliminary findings suggest that variable edge preparations result in curled chips larger in diameter than uniform edge preparations.

\section{Acknowledgements}

The authors acknowledge the support from William Shaffer and John Sockman of Conicity Technologies for providing the PCBN inserts with uniform and variable microgeometry edge preparations.

\section{References}

Altintas, Y. (2000) Metal Cutting Mechanics, Machine Tool Vibrations, and CNC Design, Cambridge University Press.

Ceretti, E., Lazzaroni, C., Menegardo, L. and Altan, T. (2000) 'Turning simulations using a three-dimensional FEM code', Journal of Materials Processing Technology, Vol. 98, pp.99-103.

Cockroft, M.G. and Latham, D.J. (1966) A Simple Criterion of Fracture for Ductile Metals, National Engineering Laboratory, Report 216.

Conicity Technologies (2006) Available at: www.conicity.com.

Endres, W.J. and Koutanya, R. (2002) 'The effects of corner radius and edge radius on tool flank wear', Transactions of NAMRI/SME, Vol. 30, pp.401-407.

Gray, G.T., Chen, S.R., Wright, W. and Lopez, M.F. (1994) Constitutive Equations for Annealed Metals under Compression at High Strain Rates and High Temperatures, Los Alamos National Laboratory Report, LA-12699-MS.

Guo, Y. and Dornfeld, D.A. (1998) 'Finite element analysis of drilling burr minimization with a backup material', Transactions of NAMRI/SME, Vol. 26, pp.207-212.

Guo, Y. and Liu, C.R. (2002) '3D FEA modeling of hard turning', ASME Journal of Manufacturing Science and Engineering, Vol. 124, pp.189-199.

Johnson, G.R. and Cook, W.H. (1983) 'A constitutive model and data for metals subjected to large strains, high strain rates and high temperatures', Proceedings of the 7th International Symposium on Ballistics, The Hague, The Netherlands, pp.541-547.

Karpat, Y. and Özel, T. (2006) 'Identification of friction factors for chamfered and honed tools through slip-line field analysis', Proceedings of 2006 ASME International Conference on Manufacturing Science and Engineering, Paper No. 21127, 8-11 October, Ypsilanti, MI.

Karpat, Y. and Özel, T. (2007) '3-D FEA of hard turning: investigation of PCBN cutting tool micro-geometry effects', Transactions of NAMRI/SME, Vol. 35, pp.9-16.

Klocke, F. and Kratz, H. (2005) 'Advanced tool edge geometry for high precision hard turning', Annals of CIRP, Vol. 54, No. 1, pp.47-50.

Liu, R. and Shih, A. (2006) 'Finite element modeling of 3D turning of titanium', International Journal of Advanced Manufacturing Technology, Vol. 29, Nos. 3-4, pp.253-261. 